\title{
PSA Level Greater than 0.4
}

National Cancer Institute

\section{Source}

National Cancer Institute. PSA Level Greater than 0.4. NCI Thesaurus. Code C153415.

A blood concentration of prostate specific antigen greater than $0.4 \mathrm{ng} / \mathrm{mL}$. 